\title{
Overriding default interpretations through prosody: Depictive predicates in Brazilian Portuguese
}

\author{
Natália Brambatti Guzzo \& Heather Goad*
}

\begin{abstract}
In Brazilian Portuguese, depictive predicates can have ambiguous readings: the attribute can either refer to the subject (high attachment; HA) or the object (low attachment; LA) of the sentence. Previous studies have found that LA is the default interpretation for ambiguous depictive predicates (e.g., Magalhães \& Maia 2006, Fonseca \& Magalhães 2007), and that speakers use different acoustic cues to signal HA. However, these studies found several mismatches between speakers' intended intonation and listeners' interpretations. We conducted a judgement task and a production task to determine which acoustic cues are used by native speakers to arrive at HA interpretation. The results for the judgement task indicate that HA interpretation is favored by pause before attribute (which can be combined with another cue in the attribute). In the production task, speakers can also signal HA by putting a pause before the attribute (which can be combined with another cue in the object). However, some of the participants did not use any acoustic cue to signal HA, which suggests that some speakers arrive at a HA interpretation only through context, not prosody.
\end{abstract}

Keywords. structural ambiguity; prosody; acoustic cues; depictive predicates; Brazilian Portuguese

1. Introduction. One of the assumptions of Prosodic Phonology is that the way in which structurally ambiguous sentences are parsed into prosodic domains helps listeners disambiguate them (Nespor \& Vogel 2007/1986). In an analysis of disambiguation of attributive adjectives in postnominal position in Italian, Nespor \& Vogel (2007/1986) propose that the parsing of material into phonological phrases $(\mathrm{PPh})$ is crucial for the signaling of one of the possible interpretations. Example (1) illustrates the disambiguation of such structures in Italian (Nespor \& Vogel 2007:262).
a. Ho visto
in svendita
degli sgabelli
[per pianoforti $]_{\mathrm{PPh}}$
for pianos
[antichi $]_{\mathrm{PPh}}$
see-PST-1SG on sale some stools
'I saw on sale some antique piano stools.'
b. Ho visto in svendita degli sgabelli
see-PST-1SG on sale some stools for pianos old
'I saw on sale some stools for antique pianos.'

In some languages, structurally ambiguous strings have a default interpretation, and thus one of the two possible prosodic phrasings is preferred. For example, in Spanish, the default interpretation for ambiguous relative clauses following a N PP sequence is that where the relative clause refers to the noun preceding the prepositional phrase (Fernández 2003); thus, in a sentence such as Alguien disparó contra la criada de la actriz que estaba en el balcón 'Someone shot the servant of the actress who was on the balcony', in which the relative clause (que estava en el balcón)

\footnotetext{
* We would like to thank Guilherme D. Garcia for helpful comments. This research was supported by grants from SSHRC and FRQSC. Authors: Natália Brambatti Guzzo, McGill University (nataliaguzzo@me.com) \& Heather Goad, McGill University (heather.goad@mcgill.ca).
} 
can refer to either the servant (criada) or the actress (actriz), the default interpretation is the one where it refers to the servant.

Crosslinguistically, the signaling of the default interpretation for ambiguous constructions does not necessarily rely on the use of any particular acoustic cue (see e.g., Fodor 2002, Jun 2003). The use of such cues, however, can help speakers to prosodically parse a given ambiguous construction in the non-default way and thus arrive at the second possible interpretation. The acoustic cues that can be used to signal the distinctions in prosodic phrasing that lead to disambiguation are pauses, changes in duration, and changes in pitch (see e.g., Jun 2003, Post 2003, Wagner 2010).

In Brazilian Portuguese (BP), sentences with depictive predicates can have ambiguous interpretations. For example, in the sentence $O$ homem procurou o cachorro sonolento 'The man looked for the dog sleepy', the attribute sonolento can refer either to the object (o cachorro) or the subject (o homem) in the sentence. In previous studies, it has been reported that, even though speakers allow subject interpretation for such predicates, object interpretation is the default (e.g., Magalhães \& Maia 2006). However, these studies have not yielded consistent results with respect to which factors help speakers override their default interpretation. Given that these studies have found that (a) both subject and object interpretation can be produced in the same way by native speakers, and that (b) there are mismatches between speakers' intended intonation and listeners' interpretations, one might conclude that prosody is not relevant for the disambiguation of depictive predicates in BP and that speakers rely instead solely on context to arrive at the appropriate interpretation.

The results of these previous studies are puzzling in view of crosslinguistic data on the disambiguation of structurally ambiguous constructions. It could be the case that depictive predicates in BP allow only one type of prosodic structure to map to two syntactic representations. However, it could also be the case that the methodology employed in the previous studies was not able to capture the influence of acoustic cues on the interpretation of depictive predicates in BP. We hypothesize that the source of the puzzling results found in previous studies is methodological. It thus follows from our hypothesis that depictive predicates can be prosodically parsed in two distinct ways, and that acoustic cues are relevant for the interpretation of the nondefault parsing.

The question that arises is then the following: If the disambiguation of depictive predicates in BP does rely on prosody, which acoustic cues signaling prosodic phrasing help speakers override their default preference for object interpretation? In this paper, we probe this issue by conducting two experiments, namely, a judgement task with auditory stimuli and a production task. As will be described below, these experiments have crucial methodological differences from previous studies.

The paper is organized as follows: In section 2, we describe the conditions that hold for ambiguity involving depictive predicates in BP, and we examine the findings of previous studies. In sections 3 and 4, we describe our judgement task and production task, respectively. Section 5 concludes.

2. Depictive predicates in Brazilian Portuguese. As mentioned, the constructions under focus in the present paper are depictive predicates in Brazilian Portuguese. In BP, sentences with depictive predicates can be ambiguous when two criteria are met: (a) the attribute is non-stative, and (b) the subject and the object have the same gender. The examples in (2) illustrate the ambiguity. Each example can have subject interpretation (high attachment; HA), or object interpretation (low attachment; LA). 
(2) a. O homem $\mathrm{HA}$ procurou o cachorro LA $_{\text {sonolento }}$ sA/LA

'The man looked for the dog sleepy.'

b. A veterinária $\mathrm{HA}_{\mathrm{A}}$ abraçou a prima $\mathrm{LA}_{\mathrm{LA}}$ nervosa $\mathrm{HA} / \mathrm{LA}$

'The veterinarian hugged the cousin nervous.'

Each interpretation is associated with a particular syntactic structure. The distinction between the two interpretations lies in where the attribute attaches: for low attachment interpretation, the attribute is in the same constituent as the object NP (3), while for high attachment, the attribute is outside the NP corresponding to the object; instead, it attaches directly to the higher VP (4). (Since the syntactic label of the higher sentence node in (3) and (4) is not relevant for the purposes of this paper, we label it simply as S.)

(3)

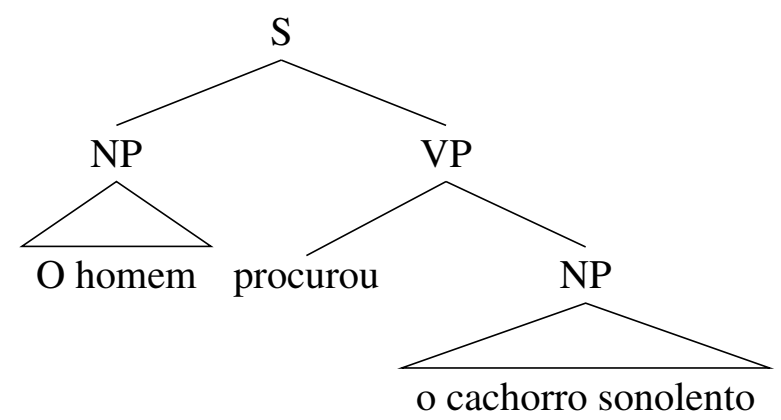

(4)

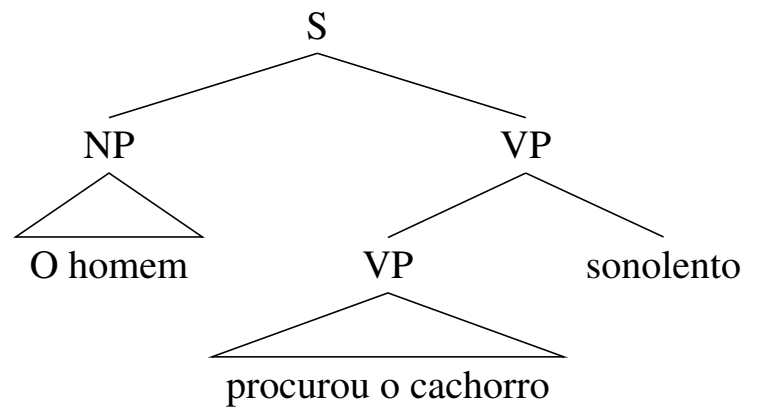

Under our hypothesis, the prosodic parsing of these sentences should mirror the syntactic differences observed between them: for low attachment the object and the attribute should form a single $\mathrm{PPh}$, while for high attachment the object and the attribute should correspond to separate PPhs (5).

a. Low attachment: $\mathrm{O}$ homem procurou [o cachorro sonolento $]_{\mathrm{PPh}}$

b. High attachment: $\mathrm{O}$ homem procurou [o cachorro $]_{\mathrm{PPh}}[\text { sonolento }]_{\mathrm{PPh}}$

However, despite the proposed differences in prosodic phrasing, these sentences can be produced in the same way, as pointed out in section 1 (see e.g., Magalhães \& Maia 2006). In other words, there are no inherent distinctions in production between them, given that both can be produced following the regular profile for declarative sentences in BP.

As mentioned earlier, previous studies on ambiguous depictive predicates have shown that, although they can be interpreted as having either HA or LA, LA is the default interpretation (e.g., Magalhães \& Maia 2006, Fonseca \& Magalhães 2007). Given that the distinction between HA and LA does not necessarily depend on different cue profiles, speakers may arrive at HA through context. However, they may also use acoustic cues to signal or arrive at the non-default interpre- 
tation. Previous studies have tried to examine which prosodic factors influence native speakers' interpretations of sentences with ambiguous depictive predicates. The next subsection reviews the main findings of such studies. As we will see, although these studies reveal certain trends in speakers' use of acoustic cues to signal the non-default interpretation, some of the results are inconsistent, which may be a consequence of the methodology employed.

2.1. Previous literature on DePictive PRediCAtes in BP. Several studies have analyzed the role of acoustic cues in the interpretation of ambiguous depictive predicates in BP. Magalhães \& Maia (2006) examined participants' interpretation preferences through a task that used orthographic stimuli. Participants were presented with sentences on a computer screen. A subset of the test sentences had simulated prosodic breaks. For these cases, participants would see the first part of the sentence and had to press a key to see its second part. Sentences with simulated prosodic breaks could have breaks either after the verb (e.g., O pai visitou \# o filho embriagado 'The father visited the son drunk') or after the object (e.g., O pai visitou o filho \# embriagado). The hypothesis was that ambiguous depictive predicates in BP would follow the Late Closure Principle, according to which local attachment (i.e., attachment within the syntactic node of the previous element) is preferred (Frazier 1979). Thus, Magalhães \& Maia (2006) predicted that having a simulated break after the verb would reinforce late closure (i.e., it would favor LA), while having a break after the object would weaken it (i.e., it would disfavor LA). However, they found that LA was preferred even for sentences with a simulated break after the object (60.42\%), although with a lower rate than for sentences with a break after the verb (81.25\%).

With respect to the sentences that had no simulated breaks, Magalhães \& Maia's (2006) participants were instructed to read some of them silently and some of them aloud before making their judgements. Low attachment was also preferred with this type of stimuli $(71.25 \%$ for silent reading; $66.25 \%$ for reading aloud). Participants' readings were acoustically examined in order to check for differences in production between LA and HA interpretations. Magalhães \& Maia (2006) found that participants used various cues to signal HA, such as pause before the attribute, lengthening of the stressed vowel in the attribute, and higher F0 in the attribute; on the other hand, they also found that some participants did not use any cue to signal HA, and that in some cases the prosody of the test sentences read aloud was not consistent with participants' own interpretations of such sentences. Thus, the results found by Magalhães \& Maia (2006) indicated that not only is LA hard to overcome, but also that speakers' do not signal HA in a consistent way.

In Magalhães \& Maia’s (2006) study, one of the possible reasons for the inconsistencies between speakers' pronunciations and interpretations lies in the fact that participants judged whether the test sentences had LA or HA based on their own spontaneous readings. In other words, the speakers were not explicitly instructed to read the sentences focusing on a particular interpretation, and so they may not have realized that they were in effect disambiguating them through their reading. Fonseca \& Magalhães (2007) conducted a follow-up study in order to examine whether speakers use acoustic cues to force disambiguation between ambiguous depictive predicates. Initially, Fonseca \& Magalhães (2007) selected four participants from Magalhães \& Maia's (2006) study, who were asked to listen to their own readings and to indicate again whether the sentences had HA or LA. Given the high rate of mismatches between the intended intonation and participants' interpretations, these participants were then asked to re-record the test sentences and to disambiguate them through their reading. These sentences were presented to other native speakers of BP, who were instructed to judge whether they had subject or object interpretations. Like in Magalhães \& Maia’s (2006) reading task, Fonseca \& Magalhães (2007) 
observed a high degree of variability in the prosodic cues used by the readers, which in turn might have influenced the relatively high rate of mismatches between the speakers' intended interpretations and the listeners' interpretations ( $50 \%)$. Similarly to what was observed in Magalhães \& Maia's (2006) productions, the acoustic cues that participants used in the rerecordings to signal HA were pause before the attribute, lengthening of the stressed vowel in the attribute, and rise in F0 in both the attribute and the subject.

Angelo \& Santos (2015) examined the role of duration in signaling interpretation differences in sentences with ambiguous depictive predicates based on an alternative hypothesis: HA is more reliably signaled by greater duration in the syllable preceding the attribute and in the initial syllable of the attribute itself. For example, in a sentence such as $O$ homem procurou $o$ cachorro sonolento 'The man looked for the dog sleepy', the underlined syllables would be longer if the attribute attached high. In this case, the increased duration would indicate that there is a prosodic boundary between the object and the attribute. Unlike previous studies, in which the target sentences were presented to participants without a context, Angelo \& Santos (2015) included their target sentences in paragraphs, which were read in full by native speakers of BP. However, the results did not confirm the hypothesis, as the combined duration of the final syllable of the object and the initial syllable of the attribute was affected differently depending on the target sentence and the speaker. This suggests that longer duration at the boundary between the $\mathrm{PPh}$ of the object and the PPh of the attribute is not used as a cue for HA.

Another proposal for disambiguation through prosodic phrasing was advanced by Gravina \& Fernandes-Svartman (2013). In their experiment, Gravina \& Fernandes-Svartman (2013) included not only depictive predicates that could refer to either the subject or the object, but also some other structurally ambiguous constructions in BP. For depictive predicates, their hypothesis was that, if there is a stress clash between the object and the attribute, stress in the object will retract if the object and the attribute are in the same $\mathrm{PPh}$. In other words, stress retraction applies if the depictive predicate has a LA interpretation, but not if it has a HA interpretation. For example, in a sentence such as João acudiu o marajá bránco 'João helped the maharajah pale', stress retraction (marája bránco) would be a strong cue for LA, while no retraction would be a cue for HA. Gravina \& Fernandes-Svartman (2013) included a production task and a judgement task in their study. The participants in the production task were told that they would record ambiguous sentences, and thus they were instructed to try to signal the two possible interpretations for each sentence through their readings. These semi-naturalistic productions were used as stimuli in the perception task, in which participants had to choose between the two possible interpretations for each sentence. Gravina \& Fernandes-Svartman (2013) found that stress retraction was a cue to low attachment in both production and perception tasks. However, they also observed that, in sentences with no stress retraction, listeners' accuracy was lower for some of the test sentences, which suggests that some participants preferred LA even when the stress profile of the construction indicated that the object and the attribute mapped to separate PPhs.

Three observations can be drawn from these previous studies: (a) as indicated above, low attachment is the default interpretation for ambiguous depictive predicates in BP, (b) LA is hard to overcome even when prosodic breaks are simulated (e.g., Magalhães \& Maia 2006), and (c) there is considerable variability in the use of prosodic cues for disambiguation as well as inconsistencies between participants' productions and their own interpretations.

The previous studies that included auditorily-based judgement tasks used participants' semi-naturalistic recordings as stimuli. In other words, the stimuli were not produced in a controlled way, following specific criteria. This might explain both the variability in responses and 
the overall preference for LA when HA was intended found in the judgement tasks reported by Magalhães \& Maia (2006), Fonseca \& Magalhães (2007) and Gravina \& Fernandes-Svartman (2013). The question that arises, then, is the following: Is it possible to override listeners' preference for LA in the interpretation of ambiguous depictive predicates in BP through the use of particular acoustic cues? A question that derives from this is the following: If listeners can overcome their default interpretation, are they also able to reliably signal HA in their speech? In order to attempt to answer these questions, we conducted two tasks, namely, a judgement task and a production task. As will be shown below, our tasks differ in two crucial ways from those previously proposed to account for the role of acoustic cues in the interpretation of ambiguous depictive predicates in BP: (i) our judgement task employed controlled stimuli, and (ii) our production task provided participants with a context for each ambiguous sentence. The following section describes the judgement task.

3. Judgement task. To test whether listeners' interpretations can be affected by the use of acoustic cues, we conducted a judgement task with auditorily-presented stimuli.

3.1. PARTICIPANTS. The participants were 23 native speakers of Brazilian Portuguese. They were all university students or university graduates, and they all spoke other languages at varying levels of proficiency. None of the participants reported any hearing impairments. All participants were tested in Montreal. To ensure that their BP had not undergone attrition due to the linguistic environment in which they lived, only native speakers who had been living in Montreal for less than six months were recruited for the experiment. None of them had lived in another country for more than three months prior to this.

3.2. STIMULI. The target stimuli $(n=12)$ consisted of sentences with ambiguous depictive predicates in BP. The target sentences were pragmatically neutral so as not to yield any interpretation biases. Filler sentences $(n=20)$ with either gender mismatch between the subject and object or obligatory low attachment (i.e., they had stative attributes) were included in the stimuli. All stimuli (both target sentences and fillers) had the shape SUBJECT + VERB + OBJECT + ATTRIBUTE.

The stimuli were recorded by a male native speaker of BP with training in linguistics and phonetics. Each test sentence was manipulated according to seven conditions with the help of Praat (Boersma \& Weenink 2017). The conditions based on which the stimuli were manipulated were decided upon through examination of the previous literature on ambiguous depictive predicates in BP (Magalhães \& Maia 2006, Fonseca \& Magalhães 2007) as well as on structural ambiguity in other languages (e.g., Fodor 2002, Jun 2003, Post 2003, Wagner 2010). Table 1 lists the seven conditions according to which the stimuli were constructed. The example sentence in Table 1 is $A$ veterinaria abraçou a prima nervosa 'The veterinarian hugged the cousin nervous'.

Sentences in the NEUTRAL condition (1) had the profile of regular declarative sentences in $\mathrm{BP}$, in which F0 falls towards the end of the sentence. Stimuli with LONGER DURATION IN ATTRIBUTE (condition 3) had the stressed vowel of the attribute lengthened to twice its original duration. The stimuli manipulated according to the fourth condition (HIGH F0 IN ATTRIBUTE) had a higher F0 throughout the attribute (in comparison to the attribute in the neutral condition), including a rise on the stressed syllable. In the sentences containing a pause (conditions 2, 5, 6, and 7 ), the pause was 0.3 seconds in length. All target sentences and fillers were manipulated according to the seven conditions in Table 1, such that the resulting number of stimuli was 224 . 
Condition

Example

\begin{tabular}{ll}
\hline 1. NEUTRAL (low F0 in attribute) & A veterinaria abraçou a prima nervosa \\
\hline 2. PAUSE AFTER VERB & A veterinaria abraçou \# a prima nervosa \\
\hline 3. LONGER DURATION IN ATTRIBUTE & A veterinaria abraçou a prima nervo:sa \\
\hline 4. HIGH F0 IN ATTRIBUTE & A veterinaria abraçou a prima nervósa \\
\hline 5. PAUSE BEFORE ATTRIBUTE & A veterinaria abraçou a prima \# nervosa \\
\hline 6. PAUSE BEFORE ATTRIBUTE + DURATION & A veterinaria abraçou a prima \# nervo:sa \\
\hline 7. PAUSE BEFORE ATTRIBUTE + HIGH F0 & A veterinaria abraçou a prima \# nervósa \\
\hline
\end{tabular}

Table 1: Conditions according to which the stimuli were constructed.

3.3. PROCEDURE. The stimuli were divided equally across two versions of the experiment, such that participants were presented with the same number of conditions regardless of which version they were assigned to. The experiment was built in Praat (Boersma \& Weenink 2017). The stimuli were pseudorandomized and presented to participants auditorily only through headphones. Each test sentence was preceded by a beep. After each sentence was played, a question would appear on the computer screen, with two possible answers provided. For example, for the sentence $A$ veterinaria abraçou a prima nervosa 'The veterinarian hugged the cousin nervous', the question was Quem estava nervosa? 'Who was nervous?'. Participants had to choose between the subject and the object by pressing a key.

Halfway through the judgement task, the participants were instructed to take a five-minute break. The task lasted approximately 35 minutes, including the break. Participants were run in a sound-attenuated booth located in the Department of Linguistics at McGill University.

3.4. Predictions. Given the seven conditions according to which the stimuli were constructed, our specific predictions for the judgement task are as follows:

(i) The NEUTRAL condition will favor LA, given that this is the default interpretation for ambiguous depictive predicates in BP.

(ii) Pauses will be good predictors of attachment site: while PAUSE AFTER VERB will favor LA, PAUSE BEFORE ATTRIBUTE will favor HA.

(iii) Having an acoustic cue in the attribute, such as LONGER DURATION or HIGH F0, will favor HA.

(iv) A combination of cues involving the attribute (PAUSE BEFORE ATTRIBUTE + LONGER DURATION, and PAUSE BEFORE ATTRIBUTE + HIGH F0) will yield the highest rates of HA in the data.

In summary, we predict that LA can be overcome through the use of specific acoustic cues that target the attribute either by enhancing a particular acoustic cue in it (such as duration or F0) or by signaling a specific prosodic parsing through a pause.

3.5. RESULTS AND ANALYSIS. Figure 1 shows the rates of HA in participants' responses for each of the seven conditions listed in Table 1. 


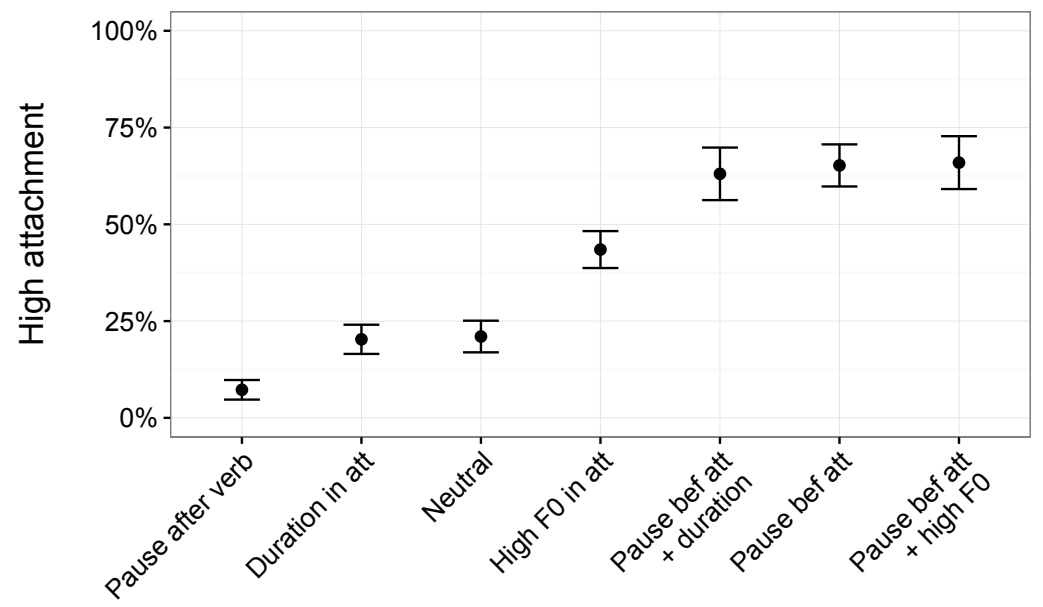

Figure 1. Percentage of high attachment in participants' responses for the seven conditions according to which the stimuli were constructed.

Three conditions have a low rate of HA in participants' judgements: PAUSE AFTER VERB (7.2\%), LONGER DURATION IN ATTRIBUTE (20.2\%), and NEUTRAL (21\%). On the other hand, three other conditions have a high rate of HA: PAUSE BEFORE ATTRIBUTE + DURATION (63\%), PAUSE BEFORE ATTRIBUTE (65\%), and PAUSE BEFORE ATTRIBUTE + HIGH F0 (65.9\%). HiGH F0 IN ATTRIBUTE has a HA rate in-between the other two groups of conditions $(43.4 \%)$.

We modeled participants' responses using multilevel logistic regressions with by-speaker and by-item random intercepts in $\mathrm{R}$ (R Core Team 2017). With HIGH F0 IN ATTRIBUTE as the reference level, the model indicated that all other conditions were significantly different from the reference level $(p<0.0001)$ : while PAUSE AFTER VERB, LONGER DURATION IN ATTRIBUTE and NEUTRAL disfavor HA $(\hat{\beta}=-2.8,-1.43,-1.36$, respectively $)$, PAUSE BEFORE ATTRIBUTE + DURATION, PAUSE BEFORE ATTRIBUTE and PAUSE BEFORE ATTRIBUTE + HIGH F0 favor HA $(\hat{\beta}=$ $1.1,1.2,1.27$, respectively). Regarding HIGH F0 IN ATTRIBUTE, these results suggest that, even though the effect of this condition is not as strong as the effect of the conditions involving a pause before the attribute, it favors HA when compared to the three conditions that disfavor this interpretation.

These results partially support the predictions presented in 3.4. The statistical analysis showed that the NEUTRAL condition disfavors HA, as suggested by Figure 1, which is consistent with prediction (i). The model also gave support to prediction (ii), according to which pauses would have an effect on participants' interpretations. As predicted, PAUSE AFTER VERB favors LA, while PAUSE BEFORE ATTRIBUTE favors HA. Since pauses signal prosodic boundaries, having a pause after the verb can be interpreted by listeners as an indication that the object and the attribute should be parsed in the same phonological phrase. On the other hand, having a pause before the attribute is an indication that the attribute corresponds to a separate phonological phrase and therefore refers to an element located higher up in the syntactic structure.

Prediction (iii), which stated that HA would be favored by having longer duration and high F0 in the attribute, is only partially supported by the data: while LONGER DURATION IN ATTRIBUTE does not favor HA, HIGH F0 IN ATTRIBUTE favors this interpretation in comparison with the conditions that disfavor it. Listeners thus seem more sensitive to changes in F0 to signal HA than to changes in duration. 
Prediction (iv) proposed that cue combination would yield the highest rates of HA. Although PAUSE BEFORE ATTRIBUTE + DURATION and PAUSE BEFORE ATTRIBUTE + HIGH F0 have high rates of HA, these conditions are not significantly different from PAUSE BEFORE ATTRIBUTE ( $p>$ 0.05 ). It thus seems that only having a pause before the attribute is enough for speakers to arrive at a HA interpretation; in other words, HA interpretation is not strengthened when PAUSE BEFORE ATTRIBUTE is combined with an additional cue. These results do not support prediction (iv).

In sum, the results of the judgement task support the idea that speakers' interpretations of ambiguous depictive predicates in BP can be affected by the use of acoustic cues. Unlike the previous studies that included judgement tasks (Magalhães \& Maia 2006, Fonseca \& Magalhães 2007, Gravina \& Fernandes-Svartman 2013), the role of each of the acoustic cues was clear in our experiment. We suggest that this is because our judgement task was controlled: the stimuli were produced by a trained native speaker and manipulated uniformly according to the seven test conditions.

In order to test whether speakers signal these differences in interpretation in their speech, we conducted a production experiment, which we describe in the next section.

4. Production task. The objective of the production task was to examine whether speakers use acoustic cues to signal specific interpretations for ambiguous depictive predicates in BP.

4.1. PARTICIPANTS AND PROCEDURE. The participants who did the production task were the same participants who did the judgement task ( $n=23$; see section 3.1).

In the production task, participants were presented with paragraphs that provided them with a context. Participants were instructed to read each paragraph to themselves, and to press a key when they were ready to proceed. Each paragraph was followed by a sentence containing a depictive predicate. Participants were instructed to read the sentence aloud once it appeared on the screen, and they were instructed to read each sentence only once. This procedure differed from previous studies on ambiguous depictive predicates in BP, in which participants either saw the test sentences in isolation (Magalhães \& Maia 2006, Fonseca \& Magalhães 2007, Gravina \& Fernandes-Svartman 2013) or within contextualizing paragraphs (Angelo \& Santos 2015). Figure 2 exemplifies a test item in the production task (contextualizing paragraph + target sentence); the contextualizing paragraph and the target sentence appeared on different screens.

\begin{tabular}{l} 
Contextualizing paragraph: \\
Por causa de um mal-entendido, a médica sem querer acabou ofendendo \\
uma enfermeira de sua equipe. Dias depois, a médica e a enfermeira iriam \\
ambas participar de uma cirurgia. A médica estava com medo de que a \\
enfermeira ainda estivesse com raiva dela e que portanto poderia prejudi- \\
car o andamento da cirurgia. \\
\hline Target sentence: \\
A médica cumprimentou a enfermeira nervosa.
\end{tabular}

Figure 2. Example of test item in the production task.

There were ten target sentences, five following a paragraph with a context that favored LA, and five following a paragraph with a context that favored HA. There were also ten fillers, which

\footnotetext{
${ }^{1}$ The translations are as follows: Contextualizing paragraph: 'Because of a misunderstanding, the doctor accidentally offended one of the nurses in her team. After a few days, the doctor and the nurse would both participate in a surgery. The doctor was afraid that the nurse would still be angry at her and thus could harm the progress of the surgery.' Target sentence: 'The doctor greeted the nurse nervous.'
} 
similarly followed contextualizing paragraphs. As in the judgement task, filler items contained either gender mismatch between the subject and the object or obligatory LA. Both target sentences and fillers had the shape SUBJECT + VERB + OBJECT + ATTRIBUTE. Participants took on average 15 minutes to complete the production task. All participants did the production task after the judgement task.

4.2. MEASUREMENTS AND PREDICTIONS. Given the results of the judgement task, in which PAUSE BEFORE ATTRIBUTE is a strong predictor for HA, we predicted that participants could also signal HA in their productions by putting a pause before the attribute. Similarly, we predicted that participants could put a pause after the verb to signal LA, since this predictor was found to significantly favor LA in the judgement task. Since LA is the default interpretation for ambiguous depictive predicates in BP, we expected participants to use pauses more frequently to signal the non-default interpretation (i.e., HA). Following these predictions, we checked participants' productions for pauses before the attribute and after the verb.

Consistent with the literature on ambiguous depictive predicates in BP, we also measured other aspects of participants' productions. The additional measurements comprised measurements for F0 and duration.

We measured F0 at several points across the sentences. Since in our judgement task HIGH F0 IN ATTRIBUTE does not favor HA as strongly as PAUSE BEFORE ATTRIBUTE, we examined whether participants used F0 to signal HA in other parts of the sentences instead. Thus, we measured peak F0 in the subject, in the object and in the attribute, as well as mean F0 and F0 at the midpoint of each of these elements. We also measured F0 at the right edge of the object, under the assumption that, if speakers put a pause between the object and the attribute, F0 could rise before the pause. Additionally, we measured the initial F0 of the attribute, under the assumption that the attribute could exhibit higher F0 from its left edge, not necessarily only in its stressed syllable.

We also measured duration at several points in the target sentences, even though LONGER DURATION IN ATTRIBUTE was not a cue for HA in our judgement task. We measured the duration of the combination of the last syllable of the object and the initial syllable of the attribute (following Angelo \& Santos 2015), the duration of the stressed vowel in the attribute (following Magalhães \& Maia 2006, Fonseca \& Magalhães 2007), and the duration of the final vowel of the object. We predicted that a longer duration on the final vowel of the object could be associated with a following pause, since lengthening before pause is a crosslinguistic tendency (see e.g., Lindblom 1968).

4.3. RESULTS. In this section, we present the trends that are robustly observed in participants' productions, since the analysis of the production data is ongoing. Productions were overall consistent within speakers, unlike what was reported in previous studies (Magalhães \& Maia 2006, Fonseca \& Magalhães 2007, Angelo \& Santos 2015). In addition, only a few cues were used across participants to signal distinct interpretations. However, as observed in previous studies, some speakers did not differentiate between LA and HA in their productions.

We start by reporting participants' productions for sentences with LA interpretation. For these cases, participants did not employ any specific acoustic cue to signal LA. In other words, these sentences had the profile of declarative sentences in BP, with a falling F0 curve toward the end of the sentence. Figure 3 illustrates the production of a sentence with LA interpretation. The sentence in Figure 3 is $A$ vendedora encontrou a diretora nervosa 'The saleswoman met the director nervous'. 


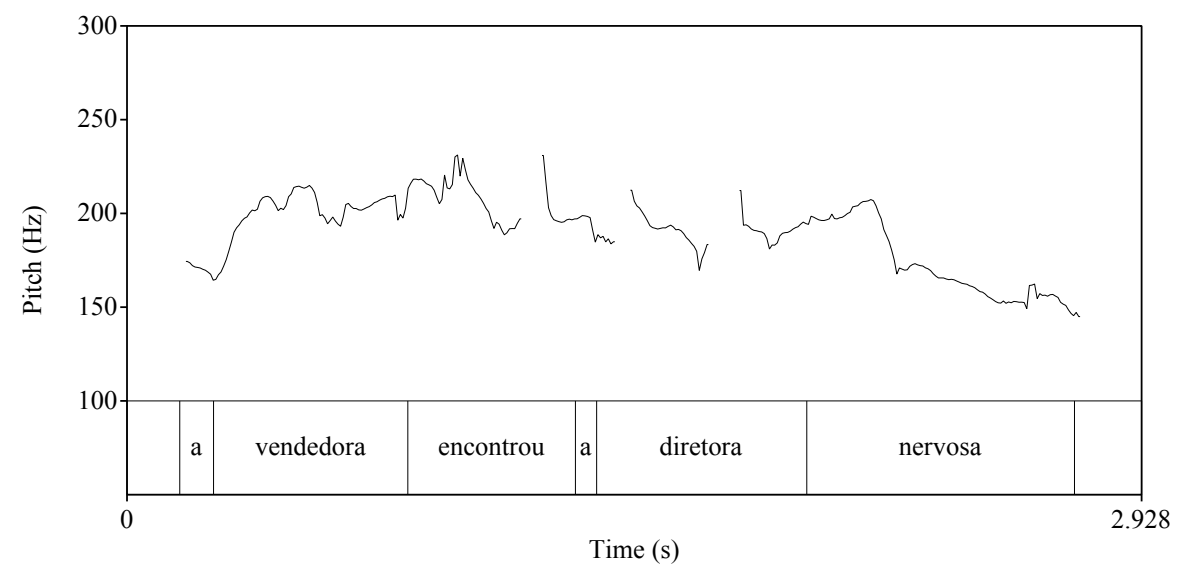

Figure 3. Production of sentence with LA interpretation.

No specific cue is used to signal LA.

This result is as expected, given that LA is the default interpretation for ambiguous depictive predicates in BP, and NEUTRAL prosody favored LA in the judgement task. However, while PAUSE AFTER VERB was the condition that yielded LA responses most frequently in the judgement task, participants did not put a pause after the verb to signal LA in their productions. Failure to use this segmentation in their own speech does not lead them, it seems, to be concerned about the potential for misinterpretation.

On the other hand, the signaling of HA interpretation involves inserting a pause before the attribute, parallel to what was observed in the judgement task. In participants' productions, pause before the attribute was combined with another cue, such as duration or F0.

This may seem surprising given that, in the judgement task, the combination of PAUSE BEFORE ATTRIBUTE and another acoustic cue did not yield the highest rates of HA. As mentioned in the previous section, the conditions in which there was cue combination did not differ statistically from PAUSE BEFORE ATTRIBUTE. The crucial difference is that, in the production task, F0 and duration were used before the pause, not in the attribute.

For example, some of the participants who put a pause before the attribute to signal HA also lengthened the final vowel of the object preceding the pause. As mentioned in section 4.2, lengthening before a pause is a crosslinguistic tendency. Figure 4 exemplifies one participant's production of HA interpretation with pause before the attribute and final lengthening of the object. The sentence in Figure 4 is $A$ medica cumprimentou a enfermeira nervosa 'The doctor greeted the nurse nervous'. 


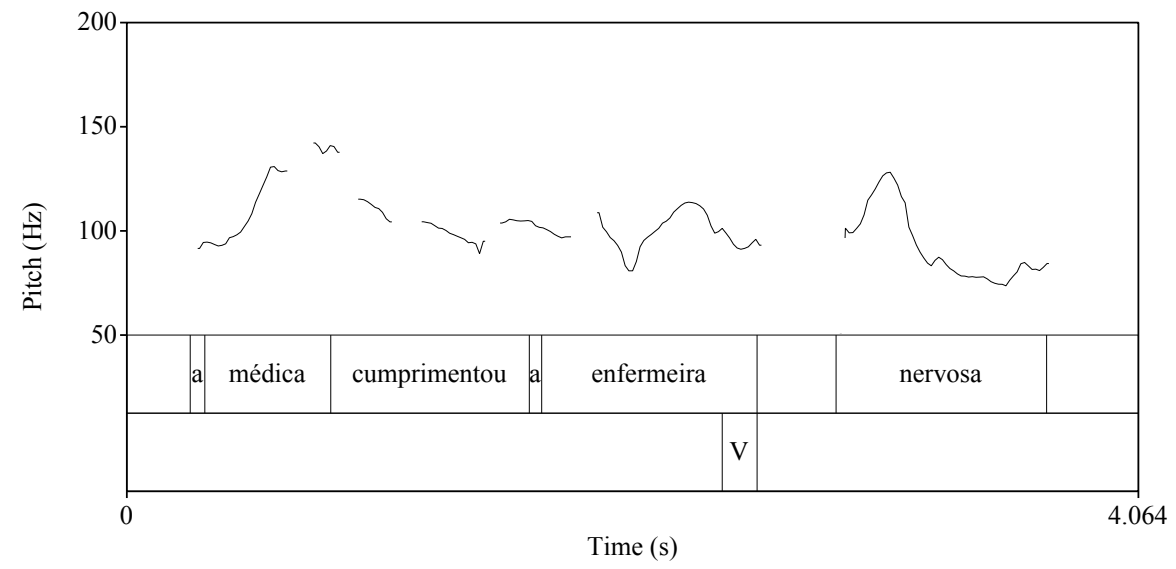

Figure 4. Production of sentence with HA interpretation. Pause before the attribute is combined with lengthening of the final vowel of the object (second tier in the text grid).

As mentioned above, some of the participants' productions with pause before the attribute to signal HA also included manipulation of F0. In this case, there was a rise in F0 at the right edge of the object preceding the pause. Figure 5 illustrates this type of production, with the same example sentence as in Figure 4.

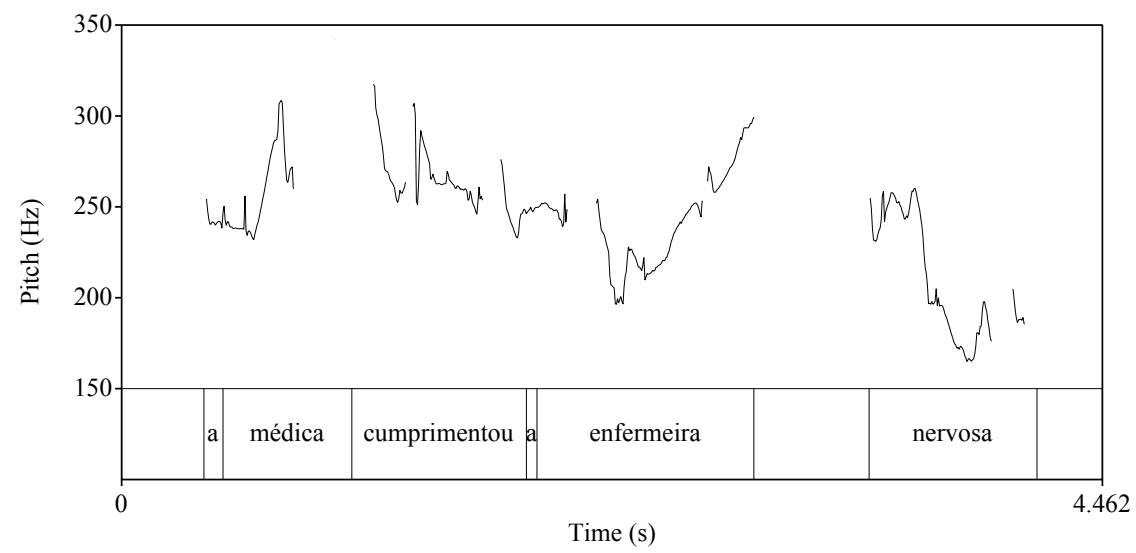

Figure 5. Production of sentence with HA interpretation. Pause before the attribute is combined with rise in $\mathrm{F} 0$ at the right edge of the object.

As indicated earlier, some of the participants did not differentiate between HA and LA in their productions. This means that their productions for HA had the profile of regular declarative sentences in BP, with lowering of F0 towards the end of the sentence. In this case, participants were possibly assuming that their interlocutors would arrive at a specific interpretation based solely on context. Figure 6 shows the production of a sentence with HA using no acoustic cue in particular to signal this interpretation. 


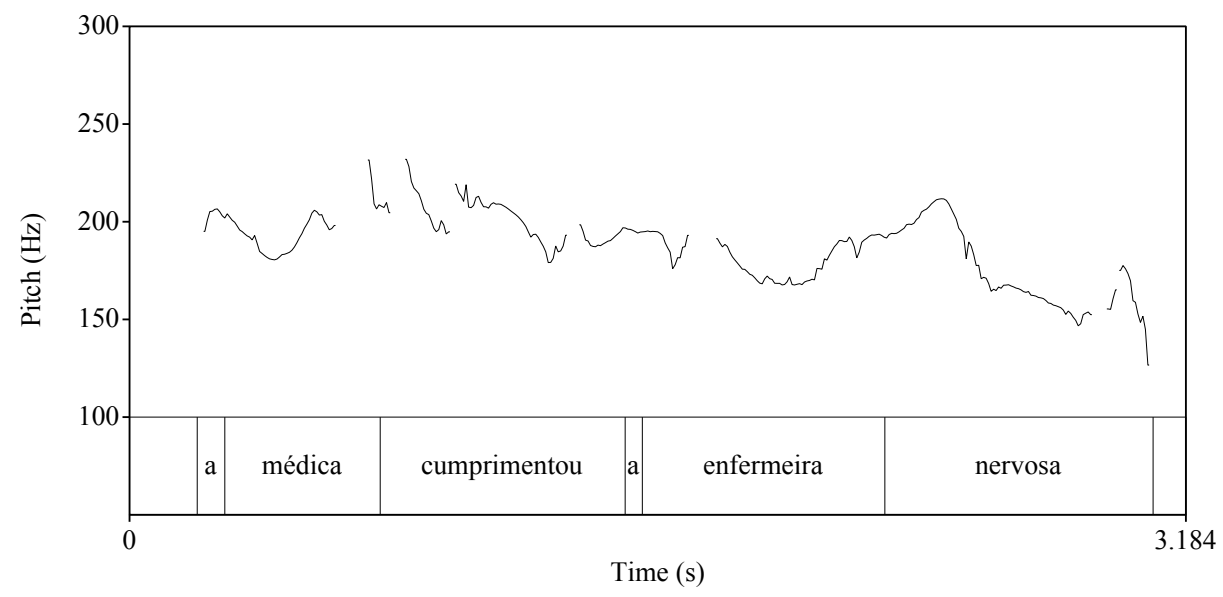

Figure 6. Production of sentence with HA interpretation.

No acoustic cue is used to signal HA.

In summary, when participants signaled HA through the use of acoustic cues, they did it by inserting a pause before the attribute, which could be combined with final lengthening of the object or a rise in F0 at the right edge of the object. However, some sentences with HA were not signaled through the use of acoustic cues, and were thus produced with the same declarative profile as the sentences with LA interpretation. The production of LA interpretation following the regular profile of declarative sentences in BP was expected, given that this is the default interpretation for depictive predicates in the language.

5. Conclusions. Previous studies on ambiguous depictive predicates in Brazilian Portuguese indicated that while low attachment is the default interpretation, high attachment can be arrived at through the use of acoustic cues. However, such studies found a high degree of variability in the acoustic cues that were used to both signal and interpret HA, as well as mismatches between speakers' pronunciations and listeners' interpretations. These inconsistent results led to questions about whether methodological factors were at play, or whether speakers/listeners rely mostly on context with a smaller role left to acoustic cues. We hypothesized that the role of acoustic cues in the disambiguation of ambiguous depictive predicates would be evident under more controlled experimental conditions.

We conducted two experiments to investigate the extent to which native speakers of BP use acoustic cues to override their default preference for LA interpretation of ambiguous depictive predicates. The experiments included a judgement task and a production task. In the judgement task, participants listened to sentences containing ambiguous depictive predicates and had to choose whether the attribute referred to the subject or the object of each sentence. The results of the judgement task showed that LA interpretation is favored by PAUSE AFTER VERB, LONGER DURATION IN ATTRIBUTE and NEUTRAL intonation, while HA is favored by PAUSE BEFORE ATTRIBUTE + DURATION, PAUSE BEFORE ATTRIBUTE and PAUSE BEFORE ATTRIBUTE + HIGH F0. HIGH F0 IN ATTRIBUTE favors HA in comparison with the three conditions that disfavor it. These results partially support our predictions (see section 3.2).

Although PAUSE AFTER VERB was the cue with the highest rate of LA in the judgement task, it was not used by participants in their productions. Instead, they produced sentences with LA interpretation using the regular profile for declarative sentences.

As mentioned above, we predicted that, in the judgement task, the highest rates of HA would be arrived at through cue combination, i.e., through a combination of PAUSE BEFORE 
ATTRIBUTE and a cue (longer duration or high F0) in the attribute. Although participants did combine cues to signal HA in their productions, the two cues that were employed did not target only the attribute. Participants combined a pause before the attribute with a cue in the object, not in the attribute: such a cue could be either a rise in F0 at the right edge of the object, or lengthening of the final vowel of the object.

Two observations can be drawn from the production results. The first one is that speakers are sensitive to the role of having a pause before the attribute in overriding the default preference for LA. This effect was also found in the judgement task. The second observation is that some of the participants did not use any particular acoustic cue to signal HA in their productions. This is an indication that, if participants are provided with an unambiguous context for ambiguous depictive predicates, some of them will rely solely on context for disambiguation, not on acoustic cues.

In summary, the results of both the judgement task and the production task indicate that prosody does play a role in disambiguating sentences with ambiguous depictive predicates in BP. The robustness of the results of our judgement task indicates that the role of prosody in the disambiguation of ambiguous depictive predicates in BP is unveiled once the stimuli are created in a controlled manner. The trends obtained in the production task also suggest that speakers are able to consistently manipulate acoustic cues in order to signal the non-default interpretation.

\section{References}

Boersma, Paul \& David Weenink. 2017. Praat: Doing Phonetics by Computer [Computer program]. Version 6.0.19.

Fernández, Eva M. 2003. Bilingual sentence processing: Relative clause attachment in English and Spanish. Amsterdam: John Benjamins.

Fodor, Janet Dean. 2002. Prosodic disambiguation in silent reading. In Mako Hirotani (ed.), Proceedings of the North East Linguistic Society (NELS) 32, pp. 113-132. University of Massachusetts, Amherst: GLSA.

Fonseca, Aline Alves \& José Olímpio de Magalhães. 2007. A interpretação de pistas prosódicas na aposição de atributos em sentenças ambíguas do PB (The interpretation of prosodic cues in the attachment of attributes in ambiguous sentences in Brazilian Portuguese). Revista de Estudos da Linguagem 15(2). 187-206. http://dx.doi.org/10.17851/2237-2083.15.2.187-206

Frazier, Lyn. 1979. On comprehending sentences: Syntactic parsing strategies. PhD dissertation, University of Connecticut.

Gravina, Aline Peixoto \& Flaviane Fernandes-Svartman. 2013. Interface sintaxe-fonologia: desambiguação pela estrutura prosódica no português brasileiro (Syntax-phonology interface: disambiguation through prosodic structure in Brazilian Portuguese). Alfa 57(2). 639668.

Jun, Sun-Ah. 2003. Prosodic phrasing and attachment preferences. Journal of Psycholinguistic Research 32. 219-249. http://dx.doi.org/10.1023/A:1022452408944

Lindblom, Bjorn. 1968. Temporal organization of syllable production. Speech Transmission Laboratory Quarterly Progress and Status Report, Stockholm.

Magalhães, José Olímpio de \& Marcus Maia. 2006. Pistas prosódicas implícitas na resolução de ambiguidades sintáticas: um caso de adjunção de atributos (Implicit prosodic cues in the resolution of syntactic ambiguities: a case of attribute attachment). Revista da ABRALIN 5. 143-167.

Nespor, Marina \& Irene Vogel. 2007/1986. Prosodic phonology. Dordrecht: Foris. 
Post, Brechtje. 2003. French phrasing and accentuation in different speaking styles. Oxford University Working Papers in Linguistics, Philology and Phonetics 8. 69-83.

R Development Core Team. 2017. R: A language and environment for statistical computing. Vienna, Austria.

Angelo, Melanie Campilongo \& Raquel Santana Santos. 2015. Prosody in Brazilian Portuguese syntactically ambiguous sentences: Duration cues. Alfa 59(2). 385-403.

http://dx.doi.org/10.1590/1981-5794-1504-7

Wagner, Michael. 2010. Prosody and recursion in coordinate structures and beyond. Natural Language and Linguistic Theory 28(1). 183-237. http://dx.doi.org/10.1007/s11049-0099086-0 